\title{
Applying UAV and photogrammetry to monitor the morphological changes along the beach in Penghu islands
}

\author{
Cheng-Hao $\mathrm{Lu}^{\mathrm{a} *}$ \\ a Dept. of Tourism and Leisure, National Penghu University of Science and Technology - luch816@ gmail.com
}

Commission VIII, WG VIII/9

KEY WORDS: UAV, beach monitoring, Digital Surface Model, Tombolo

\begin{abstract}
:
Penghu islands, in the southern Taiwan Strait, is a remnant of a middle-late Miocene basaltic shield volcano. We present a procedure to use UAV (Unmanned Aerial Vehicles) to perform photogrammetry survey and monitoring analysis in beach evolution scenarios. The aim of this study is to understand spatial-temporal change along the sandy beach in Penghu islands, especially as for the effects of typhoon and coastal structures. According to the study result, this example of application is provided to show the results and the potential of this methodology in real beach changes. In addition, we found the typhoon and coastal structures play important roles to shape the beach morphology and its evolution. The result of beach monitoring reveals that the reduction and change of sand volume in Shanshui beach resulted from the placement of detached breakwater complexes. This coastal structure likely resulted in the development of tombolo and therefor make the beach unstable and subject to conduct rip current and more erosion.
\end{abstract}

\section{INTRODUCTION}

\subsection{Research Objective}

This study is to conduct the applicability of Unmanned Aerial Vehicle (UAV) in monitoring beach landscape. The availability of Digital Surface Models (DSM) at high resolution and accuracy is very useful for the landscape monitoring by 3D reconstruction of the terrain.

Penghu islands, in the southern Taiwan Strait, is a remnant of a middle-late Miocene basaltic shield volcano. The islands are buffeted by strong northeasterly monsoons, and exposed rock has been weathered away in layers, like onions. In addition, the action of the wind has blown sand over higher areas and deposited it on the leeward slopes of those areas, forming dunes. Beach landscape has been formed by coral, seashell, and rock sand deposited by sea currents in bay areas where the currents moderate. Furthermore, beach landscape is one of most attractive tourism resource. However, owing to numerous tourists and the accompanying coastal structure may result in the degradation of beach recreational function. Therefore, this study selects a popular local beach (Shanshui beach) to conduct a comprehensive investigation of beach degradation, in order to facilitate the effective management.

\subsection{Study Area}

The investigation concerns a beach in Penghu islands (Taiwan), on the south coast of mainland (Figure 1), an area characterized by low lands and embayment. Shanshui beach is composed of the fragment of coral reef, seashell, foraminifer and basalt clasts. Shanshui beach, extending for less than 750 meters, is characterized by the presence of naturalistic sites and next to a

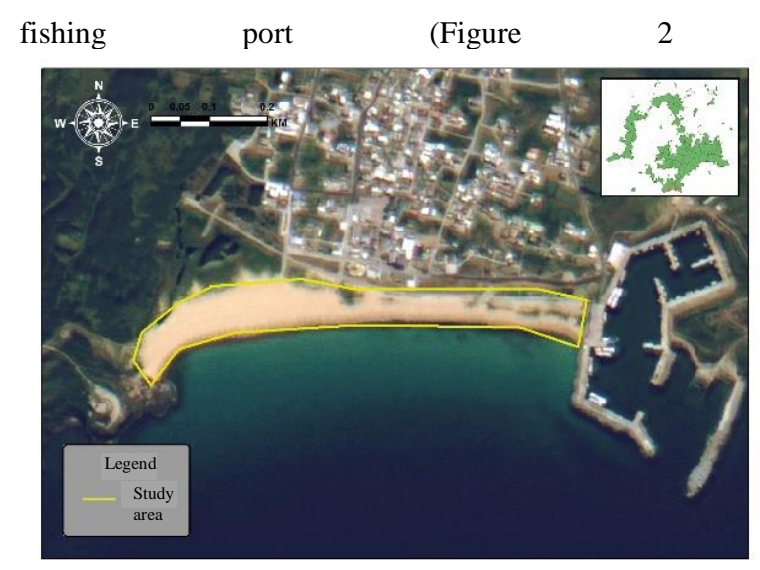

Figure 1 . The location of study area

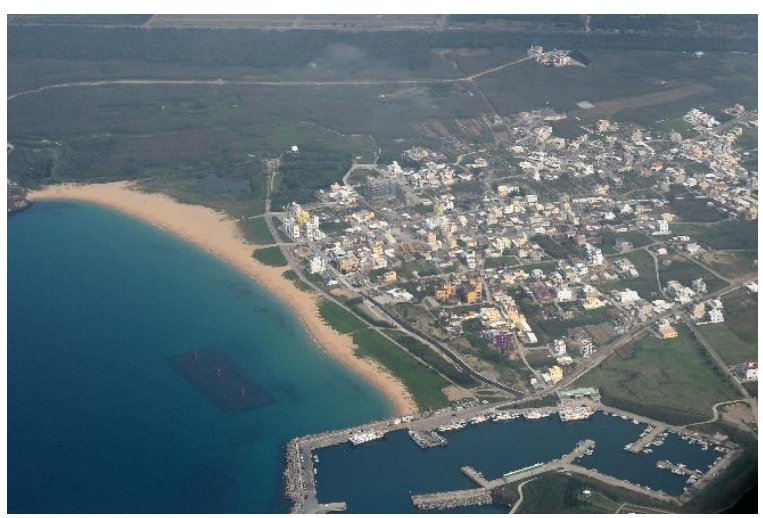

Figure 2. The Aerial Photography of Shanshui beach 


\section{METHODOLOGY}

A Net Networked Real Time Kinematic (NRTK) survey using the Virtual Reference Station (VRS) solution was carried out in 2015. The GPS survey is performed to measure eighteen 3D Ground Control Points (GCP) as Figure 3 show. The UAV system used was a 4-axis hexacopter designed and equipped with a calibrated Olympus EPL2 digital camera (Figure 4). Multiple overlapping photos ( 80 to $90 \%$ overlap) of the ground are taken as the UAV flies along an autonomous programmed flight path. The survey lines were planned using an aerial orthophoto at an average flight altitude of $50 \mathrm{~m}$ and acquisition was automatic set on one shot per second. In addition, The processing of original image collection was performed by the software package called Pix4dmapper. Figure 5 show the mesh and DSM of Shanshui beach.

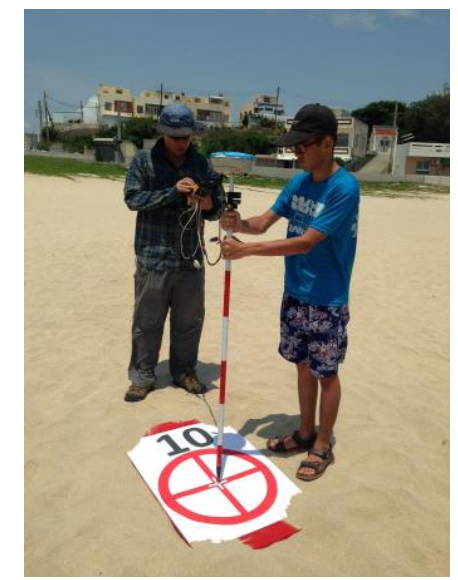

Figure 3. We used VRS system to survey the 18 GCPs

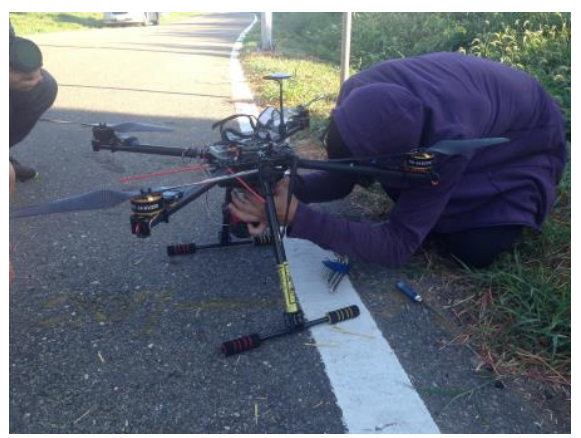

Figure 4. The UAV hexacopter
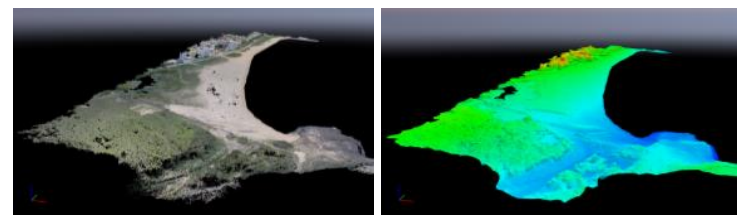

Figure 5. The mesh and DSM of Shanshui beach.

\section{RESULT AND DISCUSSION}

3.1 The typhoon and coastal structures play important roles to shape the beach morphology and its evolution

The comparsion of seasonal volumetric variations were computed to examine the degree of sand beach erosion and deposition in Shanshui beach. The result show the significant erosion after the approaching of typhoon in Summer. The observed erosion is attributed to the typhoon events. Nevertheless, the NE monsoon is the main process to recover sand beach.
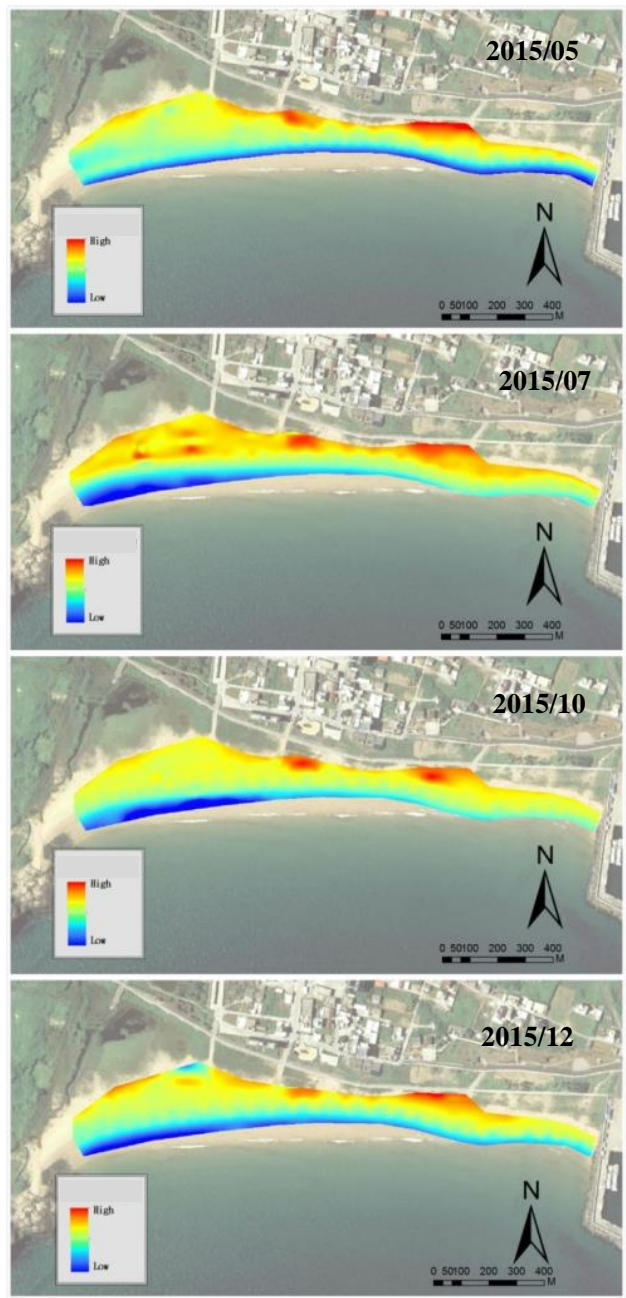

Figure 6. Multiple time series of beach DSMs 


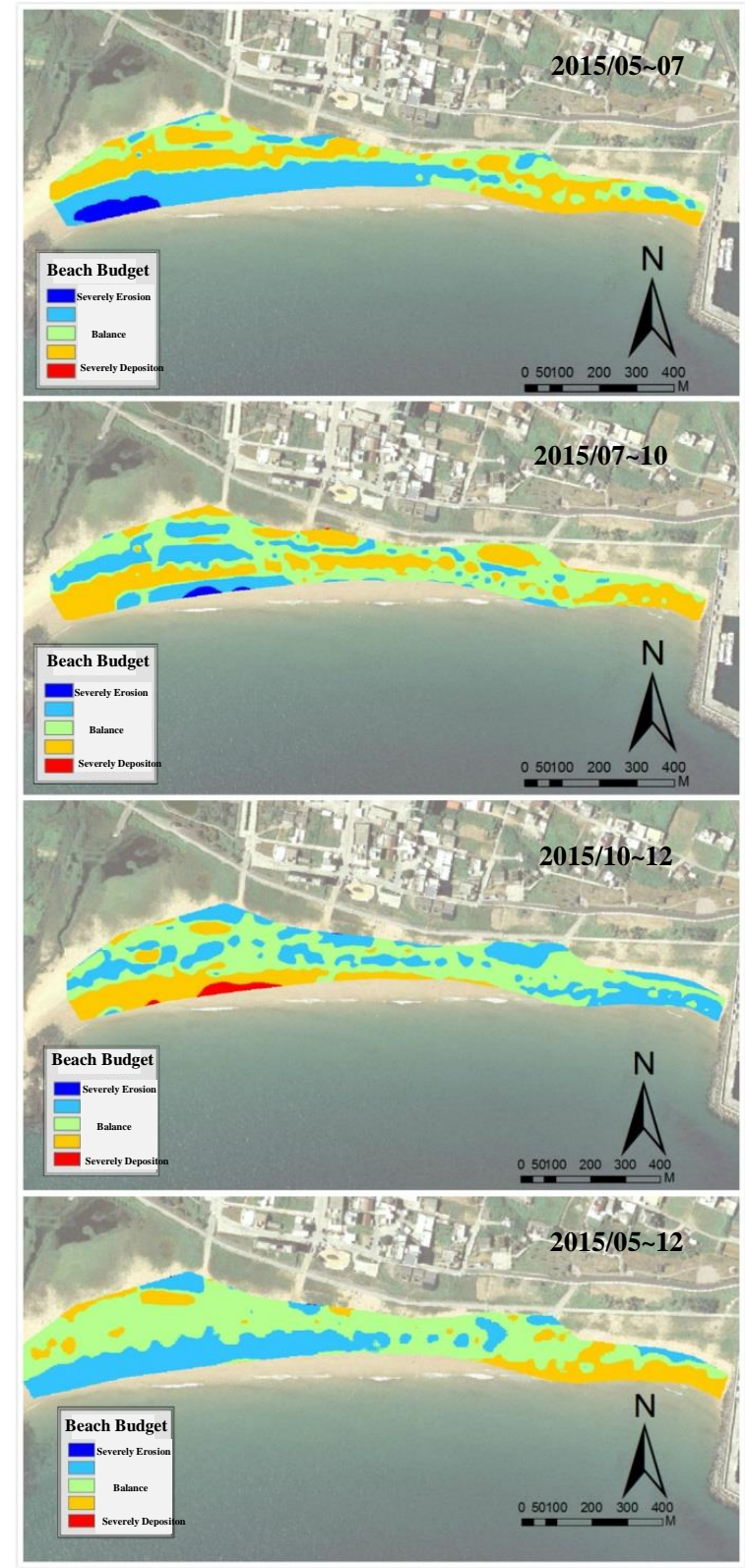

Figure7. Multiple time series of beach budgets
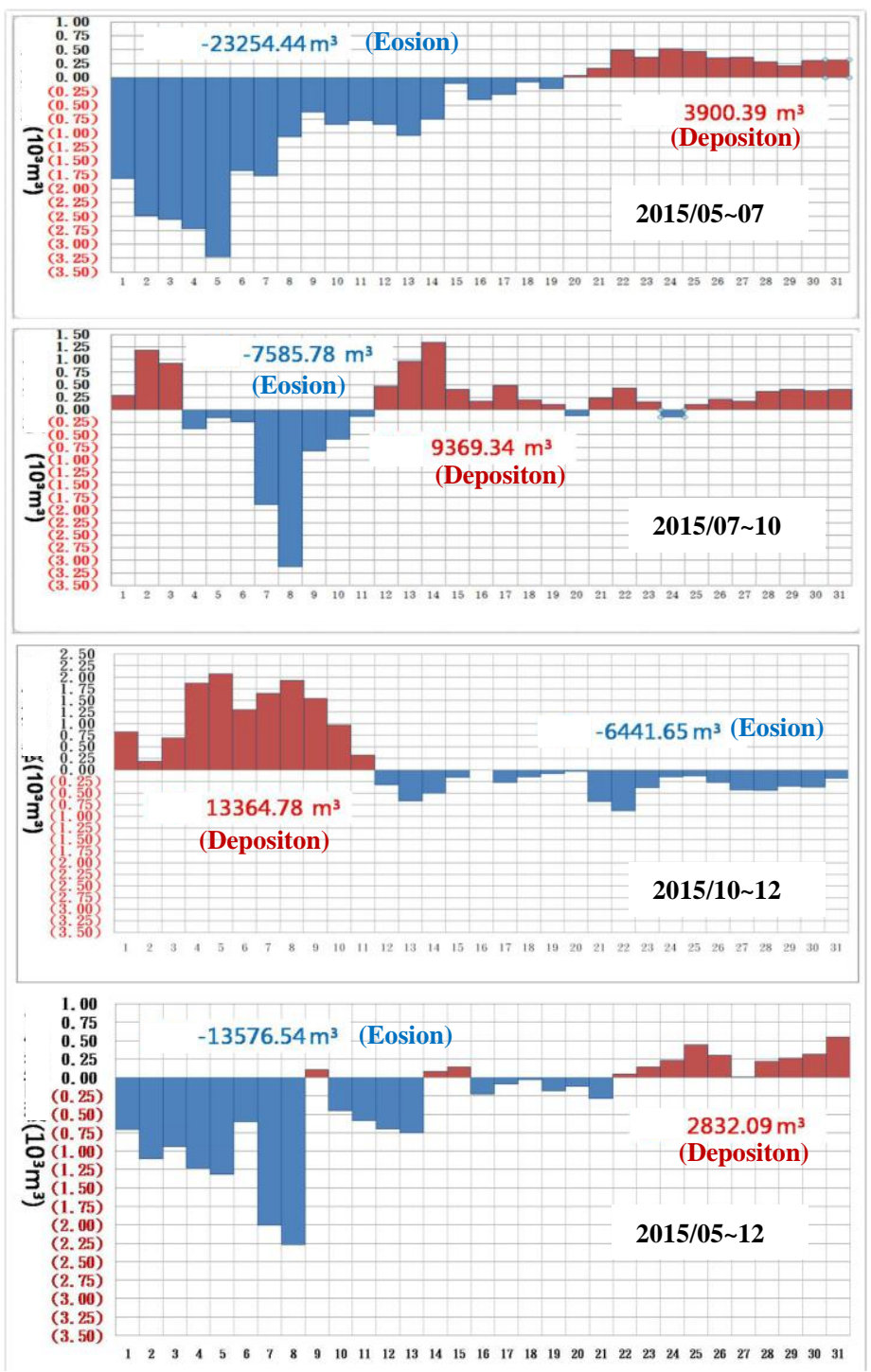

Figure 8 . The volumetric variations of beach budgets

\subsection{The development of tombolo}

The result of beach monitoring reveals, the reduction and change of sand volume in Shanshui beach resulted from the placement of detached breakwater complexes. This coastal structure likely resulted in the development of tombolo and therefor make the beach unstable and subject to conduct rip current and more erosion

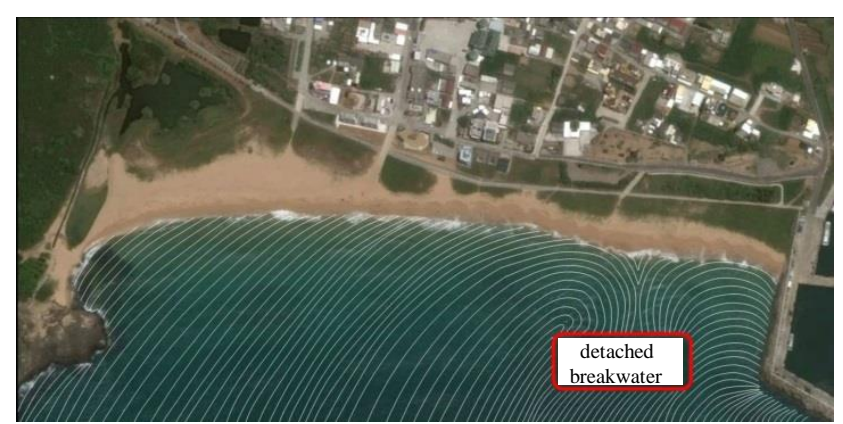

Figure 9. The simulation of wave crest after the placement of detached breakwater complexes 


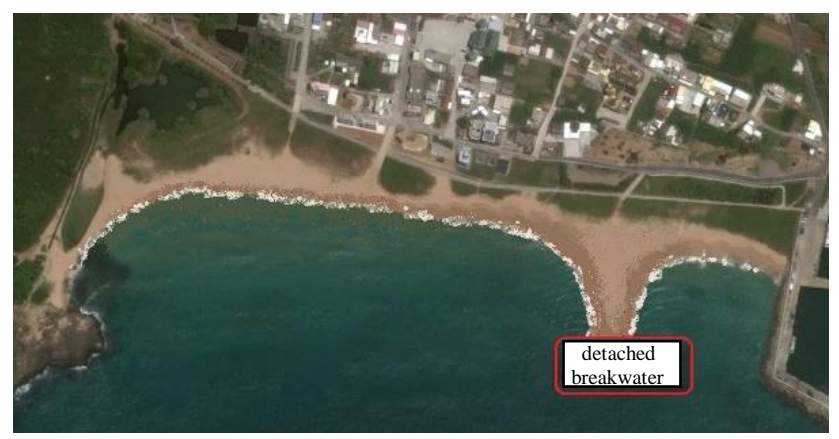

Figure 10. The simulation figure of tombolo

\section{CONCLUSSION}

This study tested the applicability of Unmanned Aerial Vehicle (UAV) in monitoring beach landscape. We used non-metric SLR digital camera and collocated with the software to reconstruct digital surface model (DSM) of the beach landscape. Results show that UAV and is applicable and reliable in monitoring coastal landscape.

The result of beach monitoring reveals, the reduction and change of sand volume in Shanshui beach resulted from the placement of detached breakwater complexes. This coastal structure likely resulted in the development of tombolo and therefor make the beach unstable and subject to conduct rip current and more erosion.

\section{REFERENCES}

Leatherman, S.P. (1997). Beach Rating: A Methodological Approach. Journal of Coastal Research, 13(1):253-258.

Luci, C. C. P., Jose, A. J., Carmen, M. \&Rauqurio, M. da C.(2003). The influence of the envirnmental status of Casa Caida and Rio Doce beaches(NE-Brazil) on beaches users, Ocean\&Coastal Management, 46:1011-1030.

Madzena, A.,Lasiak, T.(1997). Spatial and temporal variations in beach litter on the Transkei coast of south Africa. Marine Pollution Bulletin, 34(11):900-907.

Ribic, C. A.(1998). Use of indicator items to monitor marine debris on a New Jersey beach.Marine Pollution Bulletin,

36(11):887-891.

Sibson, R. (1981). "A brief description of natural neighbor interpolation (Chapter2)".In V.Barnett.Interpretin g Multivariate Data.Chichester: John Wiley. pp. 21-36.

Sunamura, T., Mizuzo, O., (1987) A study on depositional shoreline forms behind an island. Annual Report of the Institute of Geosciences, the University of Tsukuba 13:7173. 